\title{
THERMAL AND AIRFLOW CHARACTERISTICS OF TRANSITIONAL SPACES IN A TRADITIONAL URBAN FABRIC CASE STUDY OF A COVERED WALKWAY IN TIMIMOUN (SOUTH WEST OF ALGERIA)
}

\author{
KHELIFI LAMIA ${ }^{1}$, BENSALEM RAFIK ${ }^{2}$ AND SEMMAR DJAFFAR ${ }^{3}$ \\ ${ }^{1}$ Department of Architecture, Institute of architecture, University Saad Dahleb, Blida 1, Algeria \\ ${ }^{2}$ School of Architecture and Urban design, EPAU, Algiers, Algeria \\ ${ }^{3}$ Department of Energetic, Faculty of mechanics, University Saad Dahleb, Blida 1, Algeria \\ Email: khelamia@yahoo.fr
}

Revised July 2015

ABSTRACT. The research presented in this article deals with the analysis of thermal and airflow patterns in a traditional compact urban fabric called 'Ksar' located in the city of Timimoun in the South western part of the Algerian Sahara. It focuses on a particular typology of urban transitional spaces which is "a covered walkway". The aim of this research is to study the thermal and airflow characteristics of these particular spaces which affect the comfort of pedestrians and influence the ambiantal conditions of neighboring houses as well. The methodology conducted in this study consists principally in applying a computational fluid dynamics model to simulate the thermal airflow behavior of a transitional space. The computational fluid dynamics software, Fluent 6.3.26 is used for the simulation of the air flow and the temperature field traversing the streets. The results indicate that under peak Summer conditions, weak and strongly fluctuating air movements characterize the walkway and for perpendicular flow, the temperature generally decreases with an increase in velocity. Areas near the passage entrance are more affected by adverse wind conditions than other areas remote from it.

Keywords: Thermal airflow; transitional spaces; traditional architecture; numerical simulations..

1. Introduction. The acceleration in the growth rate of subtropical cities, the rising environmental problems associated with industrialization and global warming have prompted the emergency to integrate climate concerns in the design of cities for a better quality of life for the residents [1]. However, this is not possible without a deep understanding of the urban microclimate and the interaction between physical elements (wind, temperature ... etc) and urban forms in their complexity. From this view, the thermal environment is one of the main concerns to be considered in subtropical cities because of its influence on human comfort outdoor space [2]. Today knowledge is relatively well moved forward in urban climatology since it is associated with microclimatic conditions and is perfectly mastered at the level of houses and the buildings'energy performance [3]. Indeed, the aerodynamic effects, including building geometry and architecture as well as street canyon dimensions have been widely studied with wind-tunnel experiments [4], numerical models [5] and full-scale experiments [6]. However, we have a minimum knowledge on the behavior of the intermediate or transitional spaces which link building spaces to external ones in hot climate. According to Mills [7], we have to pay more attention to the needs of urban space designers (intervention in existing built form) and ensure the establishment of links between domestic air exchange building and the external environment in order to procure an improved knowledge on urban climate and its integration in urban planning.

Transitional or intermediate spaces have been studied by many researchers $[8,9,10]$. In his attempt 
to define intermediate spaces, Preamechai[9], for example, points out that the relationship between the exterior and the interior of an accommodation can not be defined only by a separation, but also by a binding and a transition. "We call transitional spaces all spaces that allow the inhabitants to establish the relationship between the inside and the outside of the slot. This relationship is extremely complex and yet we must point out that these are largely transitional spaces that provide for the locals, the action to insert the space of its housing in the urban space. " [9]

According to kray[8], in addition to the outdoor space and the interior space, there is a third type of space he calls the transitional space or intermediate space. The latter has the ability to share the same characteristics as those of the outdoor or indoor space. Through an empirical and linguistic analysis, he studied several examples of transitional spaces. Chun and al. [10] characterized three types of transitional spaces. Type I is an indoor space with a frequent interaction with the outdoor through openings. This space is subject to mechanical ventilation. Type II is a covered unconditioned space in a building dominated by outdoor conditions, while Type III is an outdoor space that is shaded. (Fig. 1).

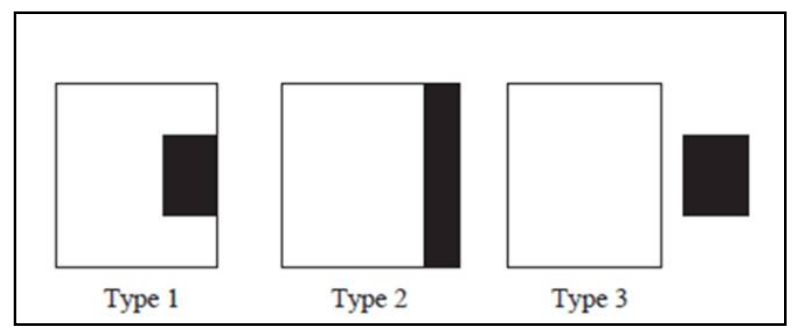

Figure 1. Three types of transitional spaces (Chun, 2004)

We focus in this study on type 2, where we discuss the walkways in the traditional fabric hot dry climate.

We consider that the walkway could be assimilated to a narrow canyon where it would be subject to quantitatively assess the climate performance of this form of urban space. The walkway is one of the bioclimatic principles that aims at creating an horizontal protection against sun and wind in a traditional urban settlement house [11]. Indeed, very few studies have surpassed the formal (qualitative) approach to quantitatively assess the climatic performance of these built forms in an arid climate. The few studies that have focused on this aspect $[12,13,14,15,16,17]$, clearly indicate that in a hot and arid environment, the thermal comfort of a pedestrian can be changed dramatically by the geometry of the street and its orientation. In summer, in the North-Southern streets, pedestrian thermal comfort can be modified by the unique geometry of the street. In the East-Western canyons however, the effect of the street's geometry is less pronounced. In winter, the North-Southern orientation allows a better penetration of solar radiation than in an East-Western direction, which leads to a better thermal comfort for the pedestrian. Wind effects however are not negligible since the discomfort of the day is less severe in the streets parallel to the wind and night cooling is more important. Combined with shading, ventilation by wind allows the improvement of Summer thermal comfort.

To date, knowledge on urban microclimates is mainly based on studies conducted in Europe and North America, and are usually associated with cold or temperate environments [7]. The strategies adopted in such climatic zones can not be applied on the hot climates of Africa and Asia where priority is given to protection against solar radiation incidents. There is also very little work on the vernacular urban structures. The study of this particular and complex urban form can provide answers to environmental stress under specific climatic conditions. [18]

In the past few years, most field studies conducted on microclimatic conditions in traditional settlements were the subject of a number of researches, mostly in hot and arid climates [12, 19, 17, 2]. However, very limited researches have been done on urban ventilation phenomena and their effects on the thermal environment in covered walkways. Kitous [2], for example, points out the dominance of the air acceleration effect in covered walkways and that the street thermal environment is strongly influenced by in-flows during Summer and Winter depending on the wind origin. Moreover, it is worth noting that the horizontal airflows induced by street intersections are often neglected. Only few studies, using both experimental and numerical approaches [20, 21, 22] describe the regions where the flow is channeled, accelerated, stagnated or re-circulated and suggest that intersections play an important role in the in-flow patterns and that they should be integrated in the urban airflow studies. Hence the importance of considering 
the street intersection effects in urban ventilation studies.

Therefore, this paper aims at understanding the thermal and airflow characteristics of transitional urban spaces in the old city of Timimoun in order to bring useful recommandations for designers. A qualitative approach was conducted in previous research [24], which highlights the relevant social role of these spaces in the life of the local inhabitants as passageways or meeting spaces, it also deduced some physical conditions of this type of configuration playing the role of both buffer space and physical link. A quantitative approach will be followed in this study based on field measurements and numerical simulation. Simulations have been performed to evaluate the microclimatic conditions in the considered area during the peak temperature Summer period.

\section{Material and methods.}

2.1.Presentation of the climatic and morphological conditions of Timimoun. Timimoun is situated in Gourara, in the south west of Algeria, on the $29^{\circ} 15^{\prime} 35.02^{\prime \prime} \mathrm{N}$ latitude and $0^{\circ} 13^{\prime} 59.51^{\prime \prime}$ E longitude from an altitude of $312 \mathrm{~m}$. (Fig.2)

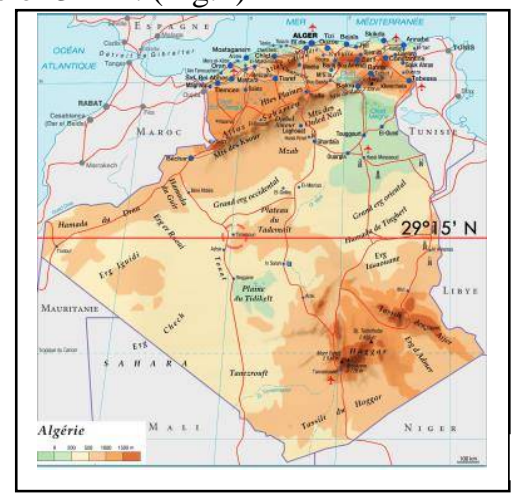

(a)

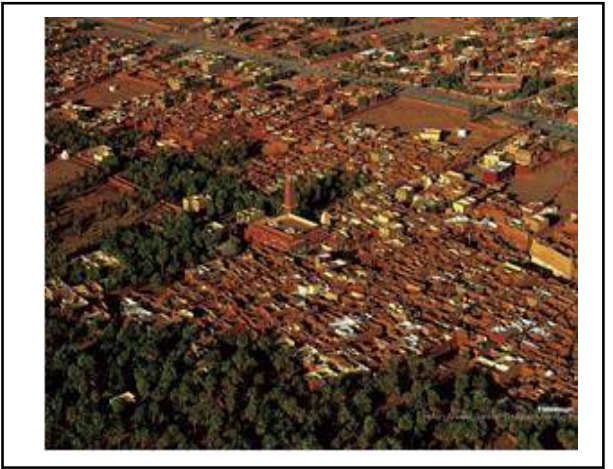

(b)

Figure 2. Geographical situation (a) and view of the ksar of Timimoun (b) (http://www.larousse.fr/encyclopedie/cartes/Algérie/1306004)

From a morphological point of view, the ksar of Timimoun is characterized by a very compact urban fabric (fig.2).The organization of this fabric is based on imbricates narrow streets . Their profiles (the height to the aspect ratio $\mathrm{H} / \mathrm{W}$ (where $\mathrm{H}$ is the buildings height and $\mathrm{W}$ the space between the buildings forming the street canyon) vary between 6 and 1.80. They seem to have different orientations (fig.3), the prevailing orientations are: the axis North East- South West for most of the streets, like the principal axis called 'El mendjour', the most permanent path in 'the ksar', the North-West, South -East axis is the alleys and dead ends. The streets are organized in a spatial hierarchy of public space and private space.

Thanks to its linearity and its development over the entire length of the Ksar, 'El mendjour' connects all entities and units that make up the latter, through the courses ('Zkak' or 'Zenka') that are perpendicular to it, with the direction of foggaras gifts.

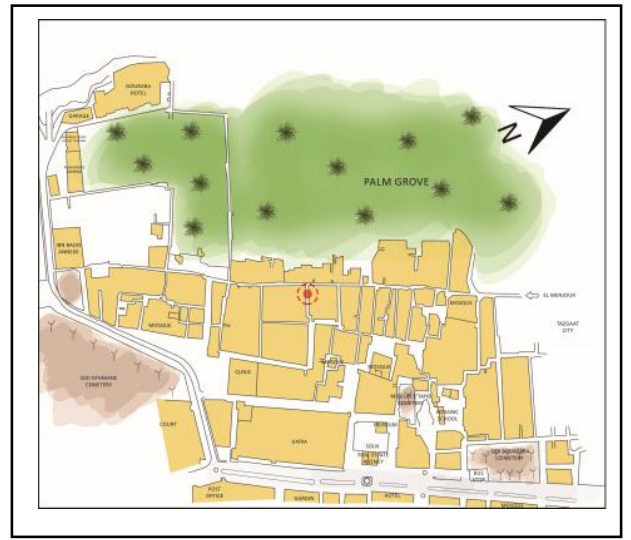

Case study 'Zenka Ouled Brahim': a narrow canyon, $\mathrm{H} / \mathrm{W}=2.66$, orientation: NW-SE, material: toub (raw earth).

Figure 3. Area of interest and case study
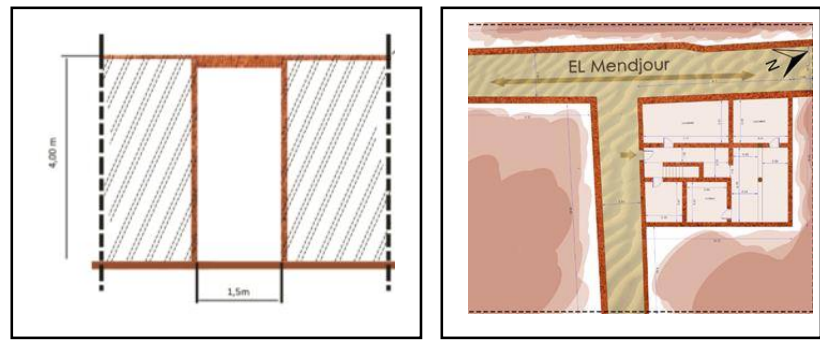

2.2. Field measurements. Measurements were performed during a hot day in June 2010 (see table 1). In 
order to characterize the thermal environment of the typical configuration of transitional spaces in the ksar of Timimoun, measurements were conducted during 2 periods (June 2010 and November 2011) in three locations from the outside (el mendjour) to the transition (a covered walkway) to the inside (habitation) (Fig. 4).

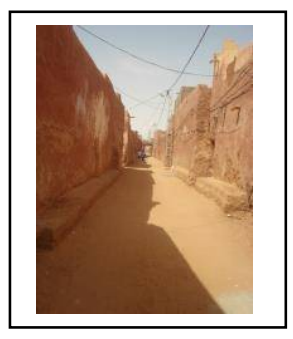

Outside (principal axis )

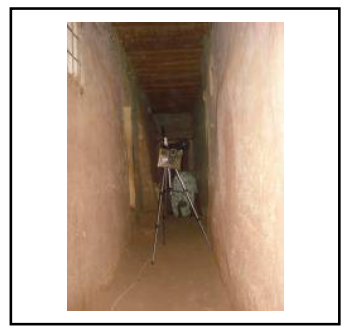

Transition (covered walkway)

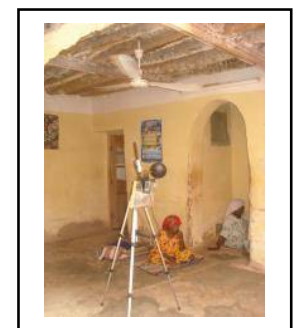

Inside

(habitation)

Figure 4: View of the measurement points' location （June 2010- November 2011)

We performed short-term measurements to determine the diurnal influence of the climate and the range of conditions occurring at a certain time. The physical variables measured included temperature, relative humidity, radiant temperature and air velocity (Table 1). Measurements were generally taken at the center of the space, from the outside to the inside of the house. These measurements were supplemented by those taken at the airport by the National Centre of Meteorology (ONM).

Table 1: Summary of all the measurements carried out

Measurements to study the thermal environment of a transitional space:

\begin{tabular}{|l|l|l|l|}
\hline Date & Time & location & method \\
\hline June 2010 & $9: 00-11: 00 \mathrm{am}$ & In the meaddle of the & Hand recording after 3 \\
& $03: 00-03: 40 \mathrm{pm}$ & street width at 1.30 m & minutes exposure \\
& $06: 00-06: 40 \mathrm{pm}$ & high. & \\
\hline
\end{tabular}

Measurement to validate the CFD model of the ksar of Timimoun area:

\begin{tabular}{|l|l|l|l|}
\hline Date & Time & Location & method \\
\hline November 2011 & $9: 00-11: 00 \mathrm{am}$ & In the meaddle of the & Hand recording after 3 \\
& 03:00- 03:40 pm & street width at 1.30 m & minutes exposure \\
& 06:00- 06: 40 pm & high. & \\
\hline
\end{tabular}

The instruments used were multi- measure portable devices (type TESTO 445 with thermos hygrometer and wind speed sensors). We also used a thermos graphic camera.

Measured climatic data were:

- $\quad$ The wind speed

- The relative humidity

- The air temperature (taken in the shade)

- The radiant temperature

- The surface temperature (thermal pictures series were conducted in parallel with insitu measurements) (fig.5)
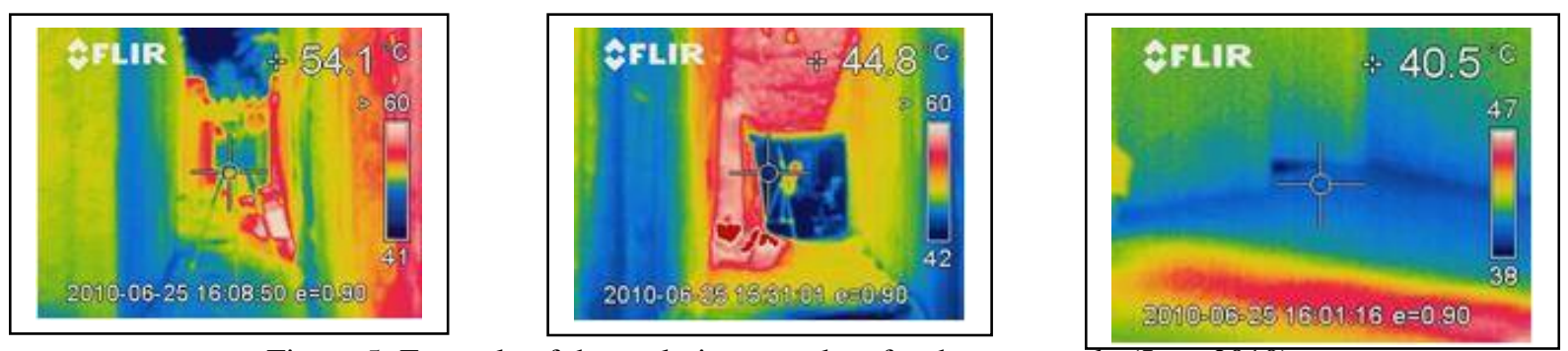

Figure 5: Example of thermal pictures taken for the case study (June 2010)

2.3. Methodology. Computational fluid dynamic (CFD) is used as the main tool for analysis and this study 
makes use of the software, fluent-6.3.26 (2006) which is based on a finite volume technique. The CFD program is a powerful tool to predict airflow in and around buildings to design a thermally comfortable indoor or outdoor environment.The software developed can further evaluate the performance of natural ventilation in a building [25]. The equations, including those concerning the conservation of mass and energy are discretised and solved iteratively. By solving these equations, the velocity and temperatures are predicted throughout the flow field. A two-dimensional computational domain is considered and the wind direction is assumed to be perpendicular to the covered walkway. A K- $\varepsilon$ turbulence model is used in an isolated street canyon. The basic transport equations of continuity, momentum and energy are shown in Table 3.

Table 3: transport equations of K- $\varepsilon$ turbulence model

Continuity equation:

$\frac{\partial \bar{U}_{i}}{\partial x_{i}}=0$

Momentum equation:

$\bar{U}_{j} \frac{\partial \bar{v}_{j}}{\partial x_{j}}=-\frac{1}{\rho} \frac{\partial \Pi}{\partial x_{i}}+\frac{\partial}{\partial x_{j}}\left[\left(v+v_{t}\right)\left(\frac{\partial \overline{U_{j}}}{\partial x_{i}}+\frac{\partial \overline{v_{i}}}{\partial x_{i}}\right)\right]-\beta g_{i} \bar{\theta}$

Thermal energy equation:

$\bar{U}_{i} \frac{\partial \theta}{\partial x_{i}}=\frac{\partial}{\partial x_{i}}\left(a+\frac{v_{t}}{\sigma \theta}\right) \frac{\partial \bar{\theta}}{\partial x_{i}}+\bar{q}_{\theta}$

Turbulence kinetic energy equation:

$\bar{U}_{j} \frac{\partial \bar{k}}{\partial x_{j}}=\frac{\partial}{\partial x_{j}}\left[\left(v+\frac{v_{t}}{\sigma_{k}}\right) \frac{\partial \bar{k}}{\partial x_{j}}\right]+v_{t}\left(\frac{\partial \bar{u}_{j}}{\partial x_{i}}+\frac{\partial \bar{u}_{i}}{\partial x_{j}}\right) \frac{\partial \bar{u}_{\bar{i}}}{\partial x_{j}}+\beta g_{i} \frac{v_{t}}{\sigma_{\theta}} \frac{\partial \bar{\theta}}{\partial x_{i}}-\bar{\varepsilon}$

Turbulence dissipation rate equation:

$\bar{U}_{j} \frac{\partial \bar{s}}{\partial x_{j}}=\frac{\partial}{\partial x_{j}}\left[\left(v+\frac{v_{t}}{\sigma_{k}}\right) \frac{\partial \bar{s}}{\partial x_{j}}\right]+\frac{\bar{s}}{\bar{k}}\left[C_{1} v_{t}\left(\frac{\partial v_{j}}{\partial x_{i}}+\frac{\partial U_{i}}{\partial x_{j}}\right) \frac{\partial \bar{v}_{i}}{\partial x_{j}}\right]-C_{2} \frac{\overline{s^{2}}}{\bar{k}}+C_{3} \frac{\bar{s}}{\bar{k}} \beta g_{i} \frac{v_{t}}{\sigma_{\theta}} \frac{\partial \bar{\theta}}{\partial x_{i}}$

Eddy viscosity equation

$v_{t}=C_{D}\left(\overline{k^{2}} / \bar{\varepsilon}\right)$

2.3.1. Boundary conditions. The boundary conditions required for the CFD simulations were mainly obtained from the weather data and field measurements. For the value of velocity inlet, a wind speed of 4 m.s-1, based on the meteorological data was used for this study. An infrared camera was used to measure the surface temperature of the exterior facades.

To validate the selected simulation tool, calculations were performed considering the boundary conditions measured during the monitoring period and simulation results were compared to the measured data (November 2011).

2.3.2. Modeling and geometry. The geometry was realized by means of Gambit. The Cartesian grid was adopted. The grid distribution in the whole domain was divided into 3 zones, regarding the positions of the spaces' boundaries. The grid of the calculation domain had the following dimensions $32(\mathrm{x}) \times 26(\mathrm{y})$ with 70806 cells and 72210 nodes (Fig 6).

3. Analysis and results.

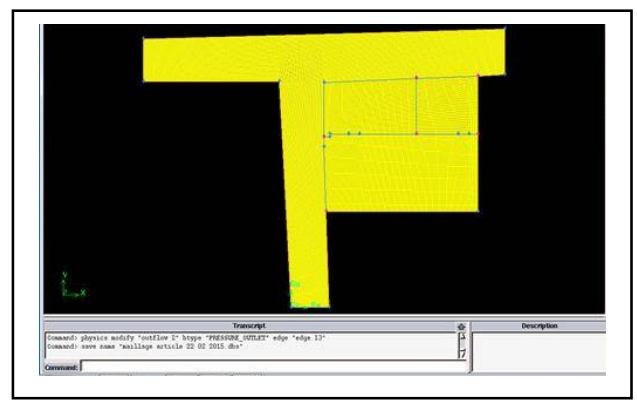

Figure 6: Display of the meshing of the case study

3.1. Effect of outflow position. Series of simulations were conducted by varying the position of outflow (outflow outside and outflow transition) in the peak summer conditions. (Table 4). 
Table 4: Effect of outflow position

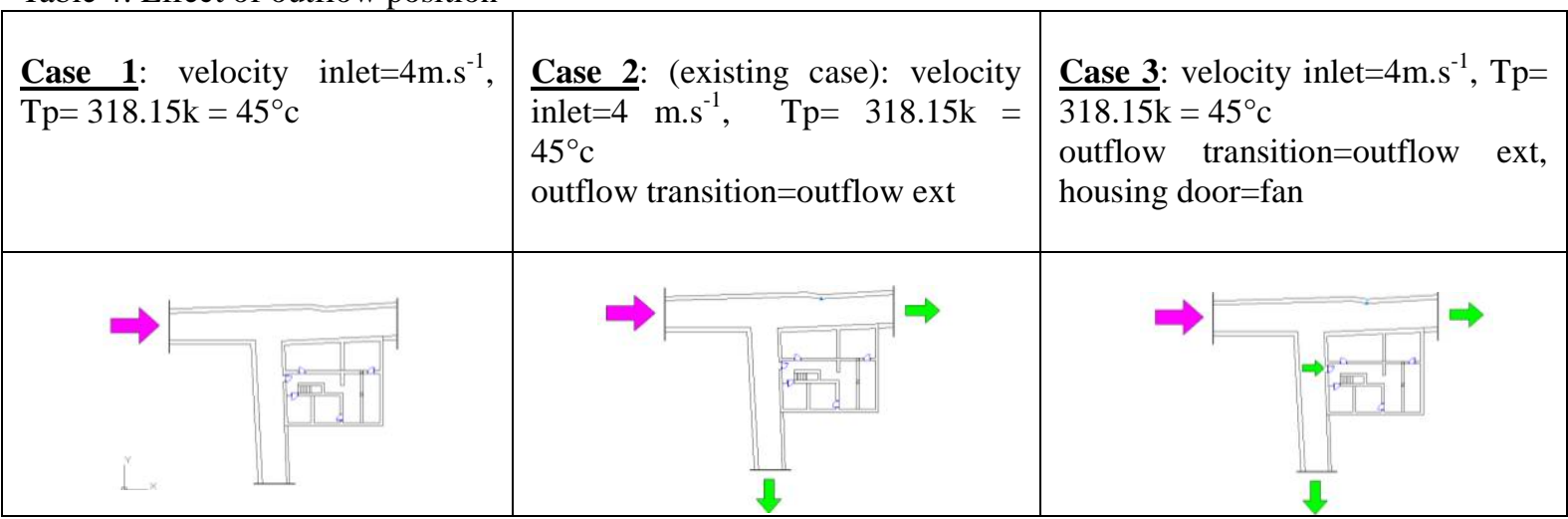

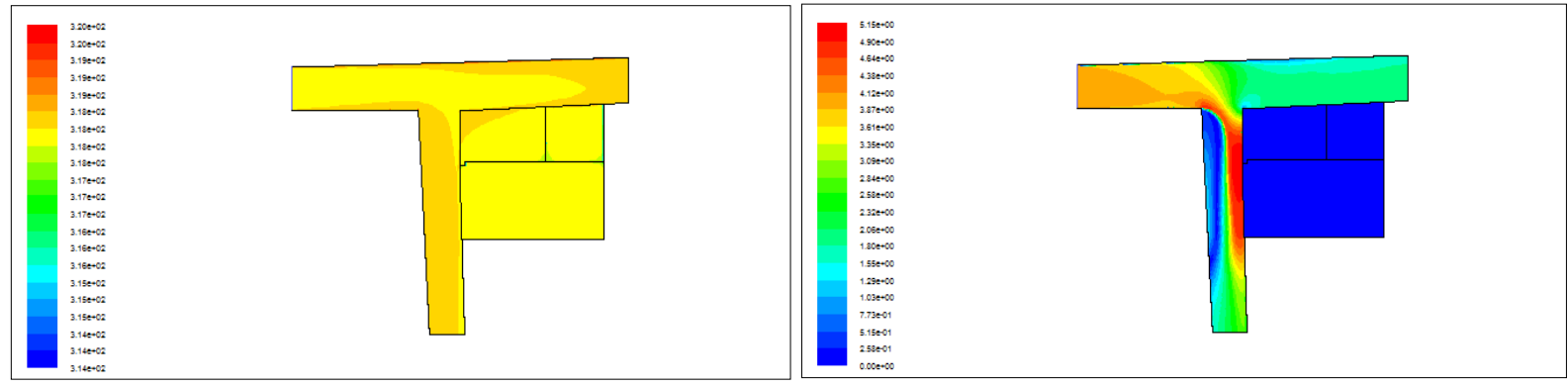

Figure 7: Temperature distribution (left) and the wind field (right) in the examined area during the summer peak conditions (case 2)
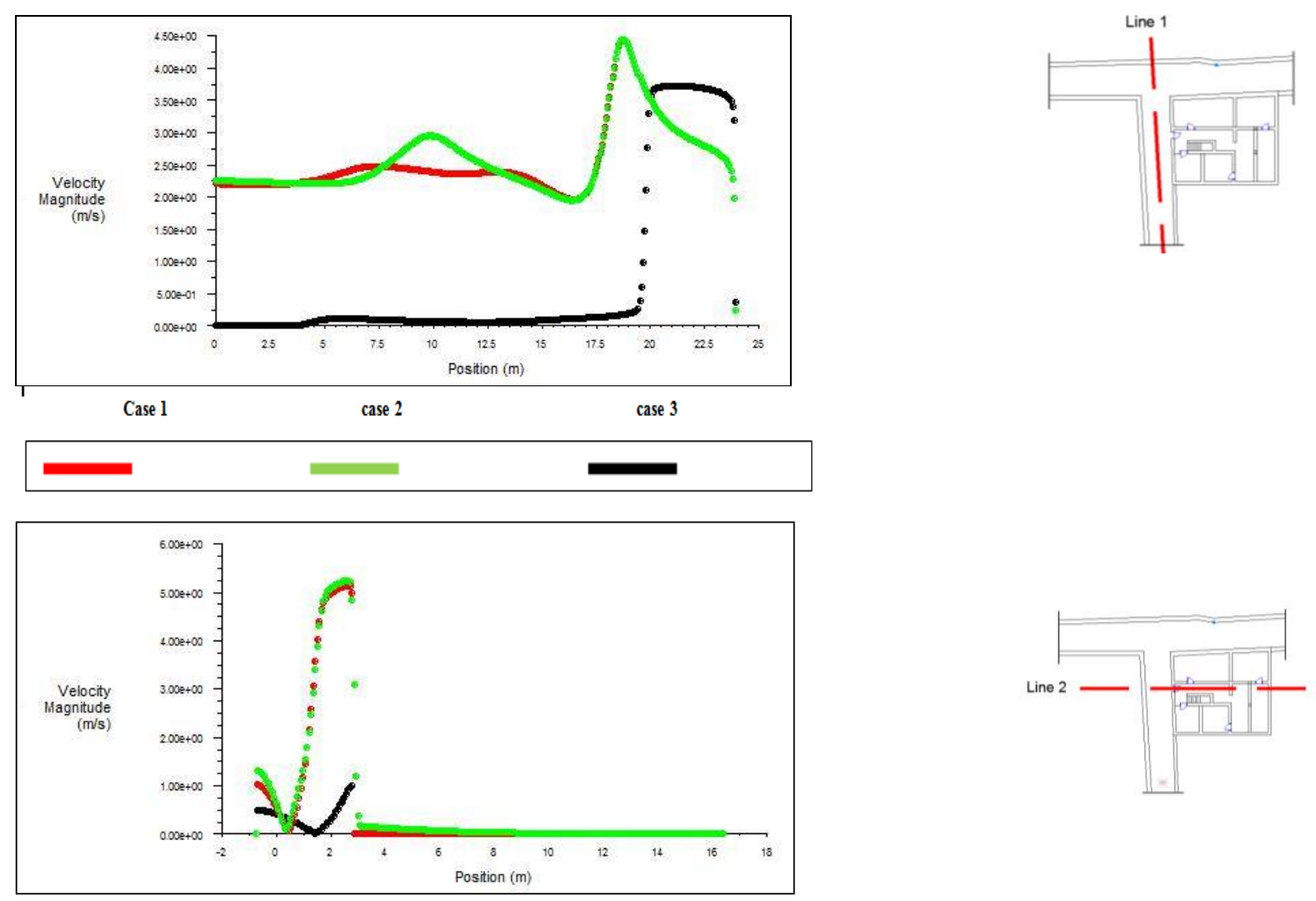

Figure 8: Velocity magnitude distribution on the walkway (according to line1 and line 2) 
General characteristics of the airflow in the covered walkway: In general, weak and strongly fluctuating air movements characterize the walkway. It is found that this form of bioclimatic protection can reduce the peak summer ambient temperature by up to $3^{\circ} \mathrm{C}$, while the corresponding surface temperatures are decreased by up to $6-9^{\circ} \mathrm{C}$. This contributes to the improvement of thermal comfort conditions in the transitional spaces and to the quality of life of the ksar inhabitants.

For the perpendicular flow, areas near the passage entrance are more drastically affected by adverse wind conditions than other areas of the passage. (conformity with the result of Stathoupoulos)[26]. We also noticed that the house kept a certain hanging freshness during Summer peak conditions.

3.2. Wind speed effect (study of the existant case). Series of simulations were conducted by varying the value of wind speed $\left(0.5 \mathrm{~m} . \mathrm{s}^{-1} 1,4 \mathrm{~m} . \mathrm{s}^{-1} 1\right.$ and $\left.10 \mathrm{~m} . \mathrm{s}^{-1}\right)$ (Table 5).

Table 5: wind speed effect (study of the existent case)

\begin{tabular}{|c|c|c|}
\hline 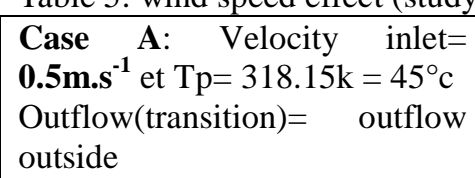 & $\begin{array}{l}\text { Case B: Velocity inlet }=\mathbf{4 m} \cdot \mathbf{s}^{-1} \text { et } \mathrm{Tp}= \\
318.15 \mathrm{k}=45^{\circ} \mathrm{c} \\
\text { Outflow }(\text { transition })=\text { outflow outside }\end{array}$ & $\begin{array}{l}\text { Case C: Velocity inlet }=\mathbf{1 0 m} \cdot \mathbf{s}^{-1} \\
\text { et } \mathrm{Tp}=318.15 \mathrm{k}=45^{\circ} \mathrm{c} \\
\text { Outflow(transition)=outflow } \\
\text { outside }\end{array}$ \\
\hline 境 & 栏 & 梓 \\
\hline
\end{tabular}

We note that very local acceleration phenomenon occurs even under weak wind conditions $(0.5 \mathrm{~m} . \mathrm{s}-1)$, within the uncovered street end (El mandjour). In this case, airflows with an average and maximum speeds are recorded under the covered walkway and at its South-West exit. These breezes are highly appreciated in Summer; they enhance the walkway ventilation and improve the pedestrian thermal comfort. This result was confirmed by Kitous [2] during the measurements in Ghardaïa under similar climatic conditions.

4. Model validation. All mathematical models need thorough validation by an alternative method; hence field measurements were used as a complementary tool for model validation. The measurements were carried out for one day over three cycles: $(9: 00 \mathrm{am}),(3: 00 \mathrm{pm})$ and $(6: 00 \mathrm{pm})$ in November 2011. The experimental measurements were compared to simulation results obtained by a special computer tool.

The comparison led to the conclusion that experimental measurements and program results were in good agreement concerning the temperature field in winter period, and the tool was subsequently used in order to perform a parametric analysis of a microclimate in urban canyons. One parameter that affects the urban canyon microclimate was examined, that was wind speed.
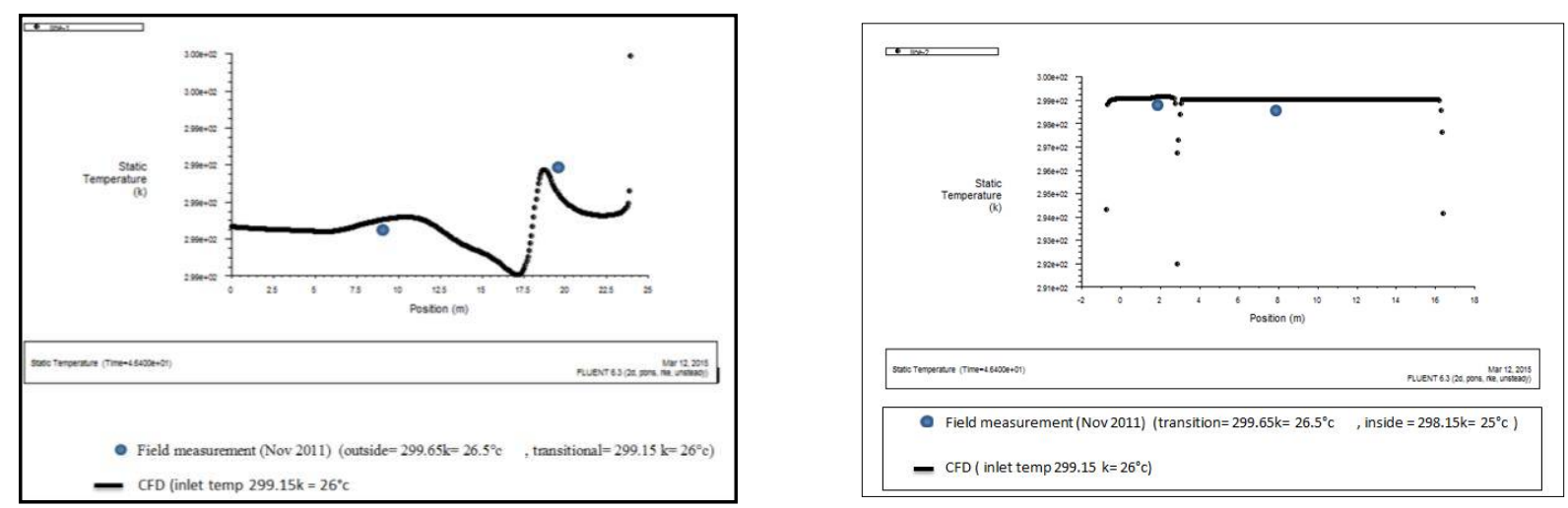

Figure 11: Temperature distribution on the transitional space in Winter peak conditions according to both axes

(November, 2011) 
Conclusion. These simulations are part of an ongoing extensive study on the evaluation of a microclimate in transitional spaces under hot and dry conditions. Some examples have been selected to point out thermal and airflow characteristics on different covered walkays in the traditional urban fabric of Timimoun (South West of Algeria). It was found that strongly fluctuating air movements characterize the walkway during peak Summer conditions and that, for perpendicular flow, the temperature generally decreases with an increase in velocity. Areas near the passage entrance are more affected by adverse wind conditions than other remote areas of the passage. Simulations also showed that the covered passageway can decrease the peak summer ambient temperatures up to $3^{\circ} \mathrm{C}$, while corresponding surface temperatures are decreased seriously. The neighbouring houses kept their freshness and good thermal conditions..

Acknowledgments. The authors wish to acknowledge the financial contribution of the Algerian-French Intergovernmental Committee. Thanks to Mr Bouraoui Mohamed and Mr Sotehi Oualid from Energetic Department of Mentouri University of Constantine for their help in CFD simulations' training.

\section{REFERENCES}

[1] Roth, M. (2007). Review of urban climate research in (sub) tropical regions. International Journal of Climatology, Vol.27; 1847-2015.

[2] Kitous, S., Bensalem, R., Adolph, L. (2012). Airflow patterns within a complex urban topography under hot and dry climate, in the Algerian sahara. Building and Environment 56 (2012), 162-175.

[3] Karava, P.(2008). Airflow Prediction in Buildings for Natural Ventilation Design: Wind Tunnel measurements and Simulation. Ph.D thesis, Department of Building, Civil, and Environmental Engineering. Concordia University Montreal, Quebec, Canada.

[4] Oke, T (1987). Boundary layer climates. 2nd ed. London, New-York: Routledge.

[5] Hunter, L.J., Johnson, G.T., Watson, I.D. (1992) An investigation of three-dimensional characteristics of flow regimes within the urban canyon. Atmospheric Environment 26B, 425-432.

[6] Louka, P., Belcher, SE., Harrison, RG. (2000) Coupling between airflow in streets and the well-developed boundary layer aloft. Atmos Environ 2000;34:2613e21.

[7] Mills, G. (2006). Progress toward sustainable settlements: a role for urban climatology. Theoretical and Applied Climatology, Vol. 84, pp. 69-76.

[8] Kray, K., Fritze, H., Fechner, T., Schwering, A., Li, R., Joy Anacta, V. (2013). Transitional spaces: between indoor and outdoor Spaces, spatial information theory, 11th International Conference, COSIT 2013, Scarborough, UK, September 2-6, 2013. Proceedings, p 14-32.

[9] Preamechai, S. (2006). Dispositifs architecturaux et mouvements qualifiés : recherche exploratoire sur les conduites sensori-motrices des passants dans les espaces publics intermédiaires.domain - other. Université Pierre Mendès-France - Grenoble II, 2006. French. <tel-00087820>. https://tel.archives-ouvertes.fr/tel-00087820, Submitted on 26 Jul 2006.

[10] Chun, Ch., Kwokb, A., Tamurac, A. (2004). Thermal comfort in transitional spaces-basic concepts: literature review and trial measurement, Building and Environment 39 (2004), 1187 - 1192.

[11] Givoni, B.(1998). Climate considerations in building and urban design. New York: Van Nostrand Reinhold.

[12] Pearlmutter, D., Bitan, A., Berliner, P. (1999). Microclimatic analysis of 'compact' urban canyons in an arid zone. Atmos Environ 1999;33:4143e50.

[13] Grundström, K., Johansson, E., Mraisi M., Ouahrani, D. (2003).Climat et urbanisme e la relation entre confort thermique et la forme du cadre bâti. Report 8. Housing Development and Management Lund University.

[14] Bourbia, F., Awbi HB. (2004).Building cluster and shading in urban canyon for hot dry climate part 1: air and surface temperature measurements. Renewable Energy 2004; 29:249e62.

[15] Ali-Toudert, F. (2005)Dependence of Outdoor Thermal Comfort on Street Design in Hot and Dry Climate, PhD thesis. Berichte des Meteorologischen Institutes der Universität Freiburg, Nr. 15, 
University of Freeburg, Germany.

[16] Pearlmutter, D., Berliner, P., Shaviv, E. (2006). Physical modeling of pedestrian energy exchange within the urban canopy. Building Environ 2006;41:783e95.

[17] Johansson, E. (2006). Influence of urban geometry on outdoor thermal comfort in a hot dry climate: a study in Fez, Morocco. Build Environ 2006;41:1326e38.

[18] Saddok, H and al. (2012). A CFD model for simulating urban flow in complex morphological street network,TOJSAT : The Online Journal of Science and Technology- January 2012, Volume 2, Issue 1).

[19] Rosenlund, H., Johansson, E., Grundstrom, K., Kortbi, M., Mraissi, M. (2000). Urban microclimate in the city of Fez, Morocco. Architecture, city, environment. In: Proceedings of PLEA 2000. Cambridge: James \& James Publisher; 2000. p. 472e6.

[20] Dobre, A., Arnold, SJ., Smalley, RJ., Boddy, JWD., Barlow, JF., Tomling, AS. (2005). Flow field measurements in the proximity of an urban intersection in London, UK.Atmos Environ 2005;39:4647e57.

[21] Carpentieri, M., Robins, AG., Baldi, S. (2009). Three-dimensional mapping of airflow at an urban canyon intersection. Boundary Layer Meteorol 2009;133:277e96.

[22] Soulhac, L., Garbero, V., Salizzoni, P., Mejean, P., Perkins RJ. (2009). Flow and dispersion in street intersections. Atmos Environ 2009;43:2981e96.

[23] SRAT, 2025. Schéma regional d'aménagement du territoire, Ministere de l'Aménagement du territoire et de l'environnement,2025 Algérie.

[24] Khelifi, L., Bensalem, R. (2010). Microclimatic conditions and thermal comfort adaptation between outdoor and indoor spaces in hot and dry climate: case study of the traditional city of Timimoun (South west of Algeria)', 4th international conference on Built Environment in Developing Countries 2010, School of housing, building and planning, Universiti Sains Malaysia (USM), 1-2 December 2010, ISBN nº78 983398660 6, www. hpb.usm.my.

[25] Chen, Q., Srebric, J. (2000). Application of CFD tools for indoor and outdoor environment design, International Journal on Architectural Science, Volume 1, Number 1, p.14-29, 2000.

[26] Stathopoulos, Th., Wu, H. (1992). Wind Environment Around Buildings: A Knowledge-Based Approach, .Journal of Wind Engineering and Industrial Aerodynamics, 41-44 (1992) 2377-2388 2377. Elsevier. 